Saudi Journal of Medicine

Abbreviated Key Title: Saudi J Med ISSN 2518-3389 (Print) IISSN 2518-3397 (Online) Scholars Middle East Publishers, Dubai, United Arab Emirates Journal homepage: http://scholarsmepub.com/sjm/

Original Research Article

\title{
Lip Prints: An Adjunct to Gender Prediction? A Study of 450 Nigerians Resident in Port Harcourt
}

\author{
Omuruka ThankGod Chukwumeka ${ }^{1}$, John Nwolim Paul ${ }^{1 *}$, Chizindu Akubudike Alikor ${ }^{2}$, Chinyere O. Ndu-Akinla ${ }^{3}$ \\ ${ }^{1}$ Department of Human Anatomy, Faculty of Basic Medical Sciences, College of Health Sciences, University of Port Harcourt, Rivers State, Nigeria \\ ${ }^{2}$ Department of Internal Medicine, University of Port Harcourt Teaching Hospital, Port Harcourt, Rivers State, Nigeria \\ ${ }^{3}$ Department of Family Medicine, Rivers State University Teaching Hospital, Port Harcourt, Rivers State, Nigeria
}

DOI: $10.36348 /$ sjm.2019.v04i11.003

| Received: 28.10.2019 | Accepted: 05.11.2019 | Published: 18.11.2019

*Corresponding author: John Nwolim Paul

\section{Abstract}

Background: Lip prints can be used in crime investigation to establish the presence of a victim or a suspect at a crime scene since they are visible with the naked eye but latent prints are not visible with naked eyes. The examination of these features is called cheiloscopy. Cheiloscopy or Quiloscopy is simply the study of the patterns produced by the lip prints and their application. Aim: This study was aimed at investigating the association between lip prints types and gender and the proportionality difference in distribution of lip prints between male and female. This study will add to the body of knowledge information on the association of gender and lip print which will be beneficial to geneticists, forensic experts, biologists and everyone who has interest in security outfits. Materials and Methods: A cross-sectional study design with 450 volunteers. Volunteer subjects were conveniently selected from across Port Harcourt Metropolis. Results and Discussions: This study suggest that lip distribution is independent of the gender and what was seen in the upper right quadrant (URQ) could be by a coincidence and not strong enough to suggest that lip print distribution is dependent on gender. Conclusion: The findings of this study suggest that Type I is the most predominant lip print type, followed by Type II among the study population. The study showed that not all quadrants exhibited gender differences in the pattern of lip prints distribution. Only a one quadrant (Upper Right Quadrant) of lip prints can be said to have gender discriminatory indicators, and this maybe a mere coincidence. Thus, suggests that lip prints may not be a good predictive tool for gender.

Keywords: Cheiloscopy, Nigeria, Port Harcourt, Pattern types, Prediction, Gender.

Copyright @ 2019: This is an open-access article distributed under the terms of the Creative Commons Attribution license which permits unrestricted use, distribution, and reproduction in any medium for non-commercial use (NonCommercial, or CC-BY-NC) provided the original author and source are credited.

\section{INTRODUCTION}

As early as 1902 Anthropologist R. Fischer noted systems of furrows on the red part of the human lips [1]. Lip prints have been defined by Saraswathi et al. [2] as normal surface slits, wrinkles and grooves generally referred to as sulci labiorum noticeable on the lips and formed between the inner labial mucosa and the outer skin. The examination of these features is called cheiloscopy [3-5]. Cheiloscopy or Quiloscopy is simply the study of the patterns produced by the lip prints and their application.

Lip prints can be used in crime investigation to establish the presence of a victim or a suspect at and a crime scene since they are visible with the naked eye but latent prints are not visible with naked eyes $[6,7]$.

The oral cavity is bounded anteriorly by a pair of sensitive mobile lips. In addition to being a muscular fold composed of skin, lips (upper and lower) also have glands and mucous membrane. The upper lip extends laterally toward the cheek from the nasolabial sulcus and the lower lip is bound inferiorly by the labiomental sulcus. The two lips are joined at the oral commissures and separated by the buccal fend $[8,9]$.

The mucosal area called Klein's zone is thrown into wrinkles and grooves. It is the characteristic patterns of this zone that give rise to lip prints. Thus, the study of these characteristic patterns (the position and classification of furrows and grooves) is the main aim of cheiloscopy [10]. Cheiloscopy, derived from the Greek word "Cheilos" (meaning lips) is a forensic investigation method which studies not only the elevations and depressions on the outside surface of lip but also the print made by the lips $[11,12]$.

Despite that lip prints involving the mobile parts of the lips, it's unique to individuals. This uniqueness in lip patterns remain the same throughout 
the lifetime of an individual. Thus, a person can make different print shapes of the lips according to pressure and direction but the size and pattern of the prints will not change [13] further explained that the uniqueness of lip print patterns depends on the relaxation and contraction of lip muscles. That is, whether the mouth is opened or closed. An open mouth shows ill-defined grooves while a closed mouth will reveal well defined print patterns and makes interpretation easy [14].

\section{Embryology of lip prints}

By the end of 4th week processes and structures from which the entire face and lips develop can be identified. During development the mandibular processes of the two sides grow toward each other and fuse in the midline to form the inferior margin of the stomatodeon which gives rise to the lower lip. The superior margin of the stomatodeum is bounded by upper lip which is formed from the maxillary process and frontonasal process. The overlying skin is derived from the ectoderm and the musculature is derived from mesoderm of the second pharangeal arch [15]. Expectedly, the lip prints also develop as the lip develops [15]; which remains unaltered from six week of intrauterine life till death [16]. However, Randhawa et al. [17] suggested that age (younger and older ages) affects the visibility and clarity of lip print.

\section{Classification of lip prints \\ Clauco Martin Santos classification}

In 1967 Santos divided the nature of wrinkles and grooves into simple and compound types. The simple type is formed only by one element and is further subdivided into four groups; a straight line, a curved line, an angled line, and a sine-shaped curve (sinusoidal). While the compound type is formed by several elements and also subdivided into bifurcated, trifurcated, and anomalous groups [18].

Table-1: Clauco Martin Santos lip print classification

\begin{tabular}{|l|l|}
\hline Simple types (formed by single element) & Composite types \\
\hline Straight line & Bifurcated \\
\hline Curved line & Trifurcated \\
\hline Angled line & Irregular \\
\hline Sine shaped line & \\
\hline
\end{tabular}

\section{Suzuki and Tsuchihashi classification}

In 1971, Suzuki and Tsuchihashi observed that there was specificity in the pattern of the lip grooves in every individual. From their findings six types of print patterns were classified according to the shapes and course of the grooves. This is the most widely accepted and commonly used classification in the investigation of lip prints [19, 20]. Hassan and Fahmy further divided the branched type (II) into proximal (a)-and distal (b) groups.

Table-2: Classification of lip prints according to Suzuki and Tsuchihashi

\begin{tabular}{|l|l|}
\hline Type & Characteristics \\
\hline Type I & Vertical, comprising of complete (end to end) longitudinal fissures/patterns \\
\hline Type I' & Incomplete longitudinal fissures \\
\hline Type II & Branching Y shaped pattern \\
\hline Type III & Criss-cross pattern \\
\hline Type IV & Reticular, fence like \\
\hline Type V & Undetermined \\
\hline
\end{tabular}

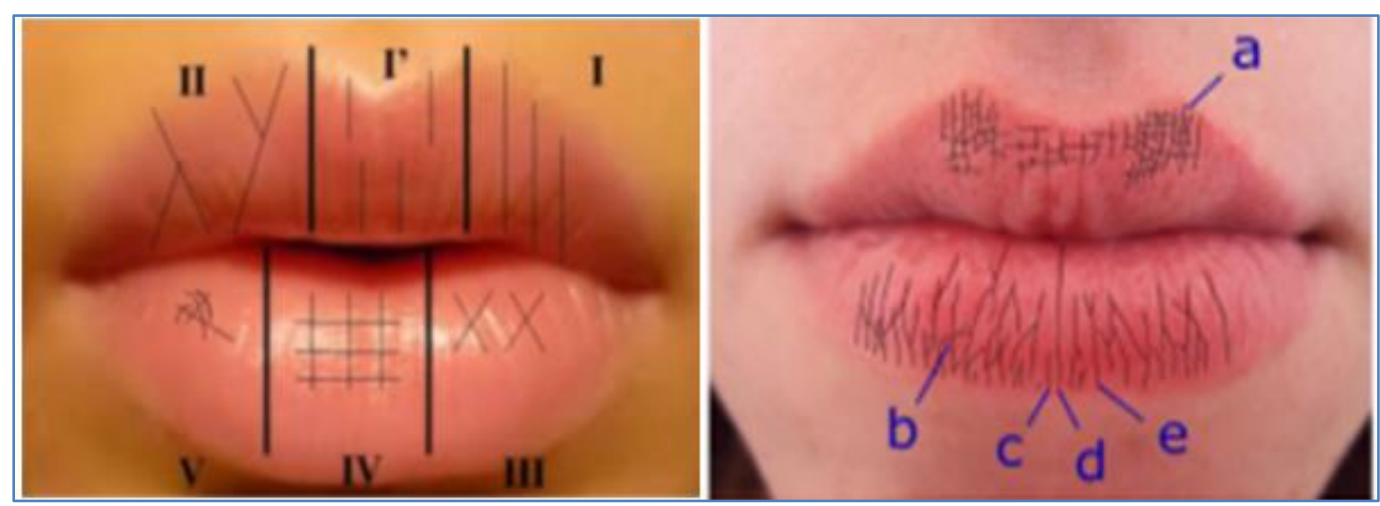

Fig-1: Photograph of lips showing different groove patterns, according to Suzuki and Tsuchihashi classification (a) Type IV or "reticular grooves"; (b) Type III or "intersecting grooves"; (c) Type I' or "incomplete vertical" grooves; (d) Type I or "complete vertical" grooves; (e) Type II or "forked" grooves. Adapted from Kannan et al. [19] and Lara et al. [20] 


\section{Renaud's classification}

After studying 4000 prints, Renaud (a French scientist) proposed a classification of lip print [5].

Table-3: Renaud's classification of lip prints

\begin{tabular}{|l|l|l|l|}
\hline Type & Description & Type & Description \\
\hline Type a & Complete vertical & Type f & Incomplete intersecting \\
\hline Type b & Incomplete vertical & Type g & Reticulated \\
\hline Type c & Complete bifurcated & Type $\mathrm{h}$ & In the form of sword \\
\hline Type d & Incomplete bifurcated & Type $\mathrm{i}$ & Horizontal \\
\hline Type e & Complete intersecting & Type $\mathrm{j}$ & Other types \\
\hline
\end{tabular}

\section{Afchar-Bayat classification}

In 1979, Afchar-Bayat proposed a lip prints classification based on groove organization [18].

Table-4: Afchar-Bayat lip print classification

\begin{tabular}{|l|l|}
\hline Type & Characteristics \\
\hline A 1: & Vertical and straight grooves, covering the whole lip \\
\hline A 2: & Like the former, but not covering the whole lip \\
\hline B 1: & Straight branched grooves \\
\hline B 2: & Angulated branched grooves \\
\hline C: & Converging grooves \\
\hline D: & Reticular pattern grooves \\
\hline E: & Other grooves \\
\hline
\end{tabular}

\section{Kasprzak classification}

Based on numerical superiority Kasprzak described ridge lines of the lip. Some researchers have proven the usefulness of this classification in practice [1]. In this classification the straight-line patterns are described as linear and denoted "L" while the bifurcated lines (bifurcate) is simply called the " $R$ " pattern. Also, if the lines are crossed, the pattern is called reticular and labelled "S" whereas the undermined patterns are denoted "N" [10].

\section{Statement of the problem}

Fingerprint analysis as a means of identification has been the popular method used by organizations, institutions and security agencies. Most documentation for the means of personal identification has been based on the fingerprint alone. There have been scientific speculations that the lip print have equal potency in unique identification as such can very well be used as much as fingerprint. Again, recent literatures have revealed that lip prints can serve as an adjunct in individual identification. It will interest one to know that researchers have not given much attention to investigating lip print and its association with gender in the course of unveiling morphological characteristics of cheiloscopy. This gap in knowledge is the reason this study was undertaken to investigate whether or not there is an association between the lip print and gender. There are a good number of works that already exist on lip print [1-20].

\section{Aim}

This study was aimed at investigating the association between lip prints types and gender and the proportionality difference in distribution of lip prints between male and female.

\section{Significance}

This study will add to the body of knowledge information on the association of gender and lip print which will be beneficial to geneticists, forensic experts, biologists and everyone who has interest in security outfits.

\section{MATERIALS AND METHODS Research design}

In this study a cross-sectional study design was adopted to determine the association between the lip print and gender among 450 individuals in the study population. Volunteer families were conveniently selected from across Port Harcourt Metropolis.

\section{Sample and sampling techniques}

Convenience sampling and sequence generated techniques were adopted for this study. The former was used due to paucity of literature on complete family size and number within the study area while the latter was to ensure randomization.

\section{Determination of sample size}

Using Cochran, (1963) sample size (SS) determination formulae for large or infinite proportion, sample size of 450 was determined.

$\mathrm{SS}=\frac{z^{2} \times p \times q}{d^{2}}$ equation II

\section{METHODS OF DATA COLLECTION}

Collection of required parameters (traits) was done with informed consent of volunteer subjects. The lip prints were obtained using print scanner (Hp G3110 Photo scanner). The scanner was powered using 
500watt solar power inverter connected to 12 volts rechargeable battery. Adopting Oghenemavwe and Osaat [21] improvised model for data capture. The surface of the digital print scanner was cleaned thoroughly with sterile wipes. The lips were placed in a way that little or no contact was made on the glass surface of the scanner. Using the photo snapping tool of the scanner the image of the lip prints were captured, this was done to ensure that lips of the subjects (volunteers) were not contaminated; prints clear and sharp yet not dented. After obtaining the lip print using the Hp G3110 photo scanner, the prints were magnified using the zooming tool on a Hp laptop connected to the scanner via USB cords. The imprints were magnified using the zooming tool on the Hp laptop connected to the scanner via USB cords, and then divided into four quadrants as upper right quadrant (URQ), upper left quadrant (ULQ), lower right quadrant (LRQ) and lower left quadrant (LLQ) to identify the predominant type of lip pattern according to Suzuki and Tsuchihashi (I, I', II, III, IV, V). The data gathered was computed in Excel sheet.

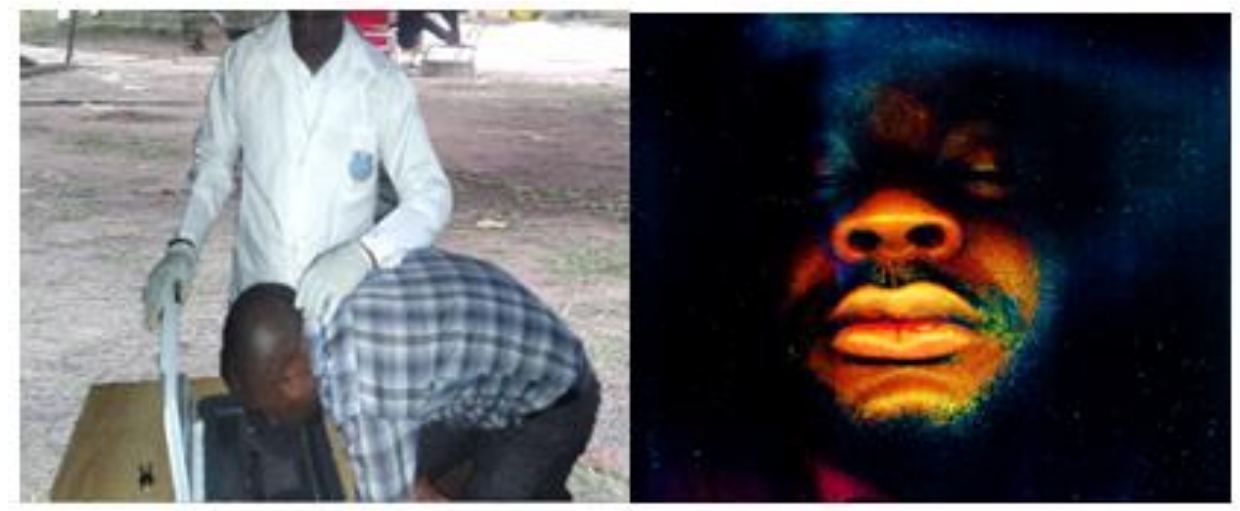

Fig-2: Illustrating the process of data collection with Hp G3110 Photo scanner from the study
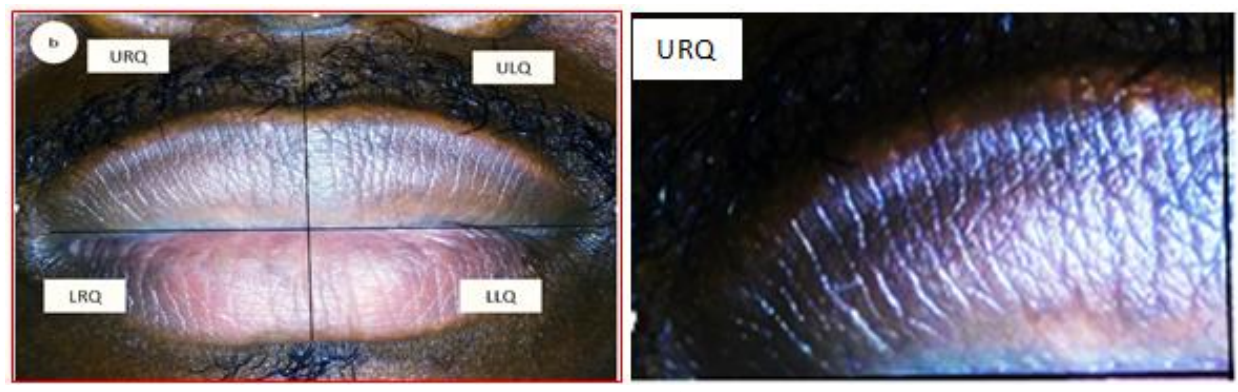

Fig-3: Lip prints capturing and extraction (Type III lip print) from the study

\section{Criteria for subject selection}

Subjects with no form of anatomical abnormality of the lip, aged between ten (10) and sixty (60) years were included while subjects with injured or scarred lips were excluded.

\section{METHODS OF DATA ANALYSIS}

Generally statistical analysis was performed using XLSTAT (Addinsoft Version 2015.4.01.21575).
Descriptive statistics was used to appropriately categorise demographic, frequency and distribution of traits. Chi-square was used to analyse association, trends and distribution difference of the traits (confidence level at 95\%).

\section{RESULTS}

Table-5: Distribution of the study population by gender

\begin{tabular}{|c|c|c|}
\hline Gender & Frequency & Percentage (\%) \\
\hline Male & 212 & 47.0 \\
\hline Female & 238 & 53.0 \\
\hline Total & $\mathbf{4 5 0}$ & $\mathbf{1 0 0 . 0}$ \\
\hline
\end{tabular}


Table-6a: Distribution of lip print types on the upper and lower lips

\begin{tabular}{|c|c|c|c|c|c|c|c|c|c|c|}
\hline & & & \multicolumn{6}{|c|}{ Lip print type } & \multicolumn{2}{|c|}{ Chi-square } \\
\hline Lip part & & $\mathbf{N}$ & Type I & Type I' & Type II & Type III & Type IV & Type V & $\mathrm{X}^{2}$ & P-value \\
\hline Upper Lip & count & 900 & 129 & 122 & 192 & 243 & 199 & 15 & & \\
\hline & $\%$ & 50 & 14.3 & 13.6 & 21.3 & 27.0 & 22.1 & 1.7 & & \\
\hline & & & & & & & & & 244.46 & $<0.01 *$ \\
\hline Lower Lip & count & 900 & 319 & 193 & 229 & 79 & 74 & 6 & & \\
\hline & $\%$ & 50 & 35.4 & 21.4 & 25.4 & 8.8 & 8.2 & 0.7 & & \\
\hline Total & count & 1800 & 448 & 315 & 421 & 322 & 273 & 21 & & \\
\hline & $\%$ & 100 & 24.9 & 17.5 & 23.4 & 17.9 & 15.2 & 1.2 & & \\
\hline
\end{tabular}

Table-6b: Distribution of lip print types in each quadrant

\begin{tabular}{|c|c|c|c|c|c|c|}
\hline Lip quadrant & Type I (\%) & Type I' (\%) & Type II (\%) & Type III (\%) & Type IV (\%) & Type V (\%) \\
\hline Upper right quadrant & $61(13.6)$ & $66(14.7)$ & $91(\mathbf{2 0 . 2})$ & $123(\mathbf{2 7 . 3})$ & $100(\mathbf{2 2 . 2})$ & $9(2.0)$ \\
\hline Upper left quadrant & $68(15.1)$ & $56(12.4)$ & $101(\mathbf{2 2 . 4})$ & $120(\mathbf{2 6 . 7})$ & $99(\mathbf{2 2 . 0})$ & $6(1.3)$ \\
\hline Lower right quadrant & $158(\mathbf{3 5 . 1})$ & $100(\mathbf{2 2 . 2})$ & $104(\mathbf{2 3 . 1})$ & $42(9.3)$ & $42(9.3)$ & $4(0.9)$ \\
\hline Lower left quadrant & $161(\mathbf{3 5 . 8})$ & $93(\mathbf{2 0 . 7})$ & $125(\mathbf{2 7 . 8})$ & $37(8.2)$ & $32(7.1)$ & $2(0.4)$ \\
\hline
\end{tabular}

Table-7a: Lip print distribution and test of association between male and female in the upper right quadrant

\begin{tabular}{|c|c|c|c|c|c|c|c|c|c|}
\hline \multirow[t]{2}{*}{ Gender } & & \multicolumn{6}{|c|}{ Upper right quadrant } & \multicolumn{2}{|c|}{ Chi-Square } \\
\hline & & $\begin{array}{c}\text { Type } \\
\text { I }\end{array}$ & $\begin{array}{c}\text { Type } \\
\text { I' }^{\prime}\end{array}$ & $\begin{array}{c}\text { Type } \\
\text { II }\end{array}$ & $\begin{array}{l}\text { Type } \\
\text { III }\end{array}$ & $\begin{array}{l}\text { Type } \\
\text { IV }\end{array}$ & $\begin{array}{c}\text { Type } \\
\text { V }\end{array}$ & $\mathbf{X}^{2}$ & P-value \\
\hline \multirow[t]{2}{*}{ Male } & Count & 38 & 29 & 47 & 61 & 32 & 5 & \multirow[t]{4}{*}{16.39} & \multirow[t]{4}{*}{$0.01 *$} \\
\hline & $\%$ within gender & 17.9 & 13.7 & 22.2 & 28.8 & 15.1 & 2.4 & & \\
\hline \multirow[t]{2}{*}{ Female } & Count & 23 & 37 & 44 & 62 & 68 & 4 & & \\
\hline & \% within gender & 9.7 & 15.5 & 18.5 & 26.1 & 28.6 & 1.7 & & \\
\hline
\end{tabular}

Table-7b: Lip print distribution and test of association between male and female in the upper left quadrant

\begin{tabular}{|c|c|c|c|c|c|c|c|c|c|}
\hline \multirow[t]{2}{*}{ Gender } & & \multicolumn{6}{|c|}{ Upper left quadrant } & \multicolumn{2}{|c|}{ Chi-Square } \\
\hline & & Type I & $\begin{array}{c}\text { Type } \\
\text { I' }\end{array}$ & $\begin{array}{c}\text { Type } \\
\text { II }\end{array}$ & $\begin{array}{l}\text { Type } \\
\text { III }\end{array}$ & $\begin{array}{l}\text { Type } \\
\text { IV }\end{array}$ & Type V & $\mathbf{X}^{2}$ & P-value \\
\hline \multirow[t]{2}{*}{ Male } & Count & 41 & 26 & 49 & 57 & 36 & 3 & \multirow[t]{4}{*}{9.45} & \multirow[t]{4}{*}{0.09} \\
\hline & \% within gender & 19.3 & 12.3 & 23.1 & 26.9 & 17.0 & 1.4 & & \\
\hline \multirow[t]{2}{*}{ Female } & Count & 27 & 30 & 52 & 63 & 63 & 3 & & \\
\hline & \% within gender & 11.3 & 12.6 & 21.8 & 26.5 & 26.5 & 1.3 & & \\
\hline
\end{tabular}

Table-7c: Lip print distribution and test of association between male and female in the lower right quadrant

\begin{tabular}{|c|c|c|c|c|c|c|c|c|c|}
\hline \multirow[t]{2}{*}{ Gender } & & \multicolumn{6}{|c|}{ Lower right quadrant } & \multicolumn{2}{|c|}{ Chi-Square } \\
\hline & & $\begin{array}{c}\text { Type } \\
\text { I }\end{array}$ & $\begin{array}{c}\text { Type } \\
\text { I' }\end{array}$ & $\begin{array}{c}\text { Type } \\
\text { II }\end{array}$ & $\begin{array}{c}\text { Type } \\
\text { III }\end{array}$ & $\begin{array}{l}\text { Type } \\
\text { IV }\end{array}$ & $\begin{array}{c}\text { Type } \\
\text { V }\end{array}$ & $\mathbf{X}^{2}$ & P-value \\
\hline \multirow[t]{2}{*}{ Male } & Count & 72 & 48 & 52 & 18 & 19 & 3 & \multirow[t]{4}{*}{2.14} & \multirow[t]{4}{*}{0.83} \\
\hline & $\begin{array}{l}\text { \% within } \\
\text { gender }\end{array}$ & 34.0 & 22.6 & 24.5 & 8.5 & 9.0 & 1.4 & & \\
\hline \multirow[t]{2}{*}{ Female } & Count & 86 & 52 & 52 & 24 & 23 & 1 & & \\
\hline & $\begin{array}{l}\text { \% within } \\
\text { gender }\end{array}$ & 36.1 & 21.8 & 21.8 & 10.1 & 9.7 & 0.4 & & \\
\hline
\end{tabular}

Table-7d: Lip print distribution and test of association between male and female in the lower left quadrant

\begin{tabular}{|c|c|c|c|c|c|c|c|c|c|}
\hline \multirow[t]{2}{*}{ Gender } & & \multicolumn{6}{|c|}{ Lower left quadrant } & \multicolumn{2}{|c|}{ Chi-Square } \\
\hline & & $\begin{array}{c}\text { Type } \\
\text { I }\end{array}$ & $\begin{array}{c}\text { Type } \\
\text { I' }\end{array}$ & $\begin{array}{l}\text { Type } \\
\text { II }\end{array}$ & $\begin{array}{c}\text { Type } \\
\text { III }\end{array}$ & Type IV & Type V & $\mathbf{X}^{2}$ & P-value \\
\hline \multirow[t]{2}{*}{ Male } & Count & 74 & 45 & 63 & 12 & 16 & 2 & \multirow[t]{4}{*}{6.24} & \multirow[t]{4}{*}{0.28} \\
\hline & \% within gender & 34.9 & 21.2 & 29.7 & 5.7 & 7.5 & 0.9 & & \\
\hline \multirow[t]{2}{*}{ Female } & Count & 87 & 48 & 62 & 25 & 16 & 0 & & \\
\hline & \% within gender & 36.6 & 20.2 & 26.1 & 10.5 & 6.7 & 0.0 & & \\
\hline
\end{tabular}


In table 5 the distribution of the study population showed that $212(47 \%)$ were males while $238(53 \%)$ were females. 300 parents comprising of 150 fathers and 150 mothers were used in the study (Tables 4.1a); with 150 offspring, comprising of 62 (41.3\%) male (boys) and 88 (58.7\%) female (Tables 4.1b).

In table $6 a$, the distribution of the lip print types on the upper and lower lips of study population was presented. Five (5) Lip print types were observed in the study population as follows: Type I, Type I', Type II, Type III, Type IV and Type V in the upper and lower lips respectively. Lip print types and proportions as observed in the upper and lower lips include Type I (Upper $=129,14.3 \%$; Lower $=319,35.4 \%)$, Type I' $($ Upper $=122,13.6 \%$; Lower $=193,21.4 \%)$, Type II $($ Upper $=192,21.3 \%$; Lower $=229,25.4 \%)$, Type III $($ Upper $=243,27.0 \%$; Lower $=79,8.8 \%)$, Type IV $($ Upper $=199,22.1 \%$; Lower $=74,8.2 \%)$, Type V (Upper $=15,1.7 \%$; Lower $=6,0.7 \%)$.

In table $6 b$, distribution of lip print types showed that in the upper right quadrant (URQ) 61 $(13.6 \%)$ of the subjects had Type I, $66(14.7 \%)$ had Type I', 91 (20.2\%) had Type II, 123 (27.3\%) had Type III, $100(22.2 \%)$ had Type IV, $9(2.0 \%)$ had Type V. What was seen in the upper left quadrant (ULQ) are as follows; 68 (15.1\%) Type I, 56 (12.4\%) Type I', 101 (22.4\%) Type II, 120 (26.7\%) Type III 99 (22.0\%) Type IV, 6 (1.3\%) Type V. Lower right quadrant (LRQ) of subjects revealed the following; 158 (35.1\%) Type I, 100 (22.2\%) Type I', 104 (23.1\%) Type II, 42 (9.3\%) Type III, 42 (9.3\%) Type IV, 4 (0.9\%) Type V. Also observing the distribution in the lower left quadrant (LLQ), 161 (35.8\%) had Type I, 93 (20.7\%) Type I', 125 (27.8\%) Type II, 37 (8.2\%) Type III, 32 (7.1\%) Type IV, $2(0.4 \%)$ Type V.

In table 7a, distribution and association between lip print types and sex in the upper right quadrant was presented as follows; Type I [males (M) = $38,17.9 \%$; females $(\mathrm{F})=23,9.7 \%)]$, Type I' $(\mathrm{M}=29$, $13.7 \% ; \mathrm{F}=37,15.5 \%)$, Type II $(\mathrm{M}=47,22.2 \% ; \mathrm{F}=$ $44,18.5 \%)$, Type III $(\mathrm{M}=61,28.8 \% ; \mathrm{F}=62,26.1 \%)$, Type IV $(\mathrm{M}=32,15.1 \% ; \mathrm{F}=68,28.6 \%)$, Type $\mathrm{V}(\mathrm{M}=$ $5,2.4 \% ; \mathrm{F}=4,1.7 \%),\left(\mathrm{X}^{2}=16.39, \mathrm{P}=0.01\right)$.

In table $7 b$, distribution and association between lip print types and sex in the upper left quadrant was presented as follows; Type I $(M=41$, 19.3; $\mathrm{F}=27,11.3 \%)$, Type I' $(\mathrm{M}=26,12.3 \% ; \mathrm{F}=30$, $12.6 \%)$, Type II $(\mathrm{M}=49,23.1 \% ; \mathrm{F}=52,21.8 \%)$, Type III $(\mathrm{M}=57,26.9 \% ; \mathrm{F}=63,26.5 \%)$, Type IV $(\mathrm{M}=36$, $17.0 \% ; \mathrm{F}=63,26.5 \%)$, Type $\mathrm{V}(\mathrm{M}=3,1.4 \% ; \mathrm{F}=3$, $1.3 \%),\left(X^{2}=9.45, P=0.09\right)$.

In table $7 \mathrm{c}$, showed the distribution and association between lip print types and sex in the lower right quadrant were as follow: Type I $(\mathrm{M}=72,34.0 \%$; $\mathrm{F}=86,36.1 \%)$, Type I' $(\mathrm{M}=48,22.6 \% ; \mathrm{F}=52$,
$21.8 \%)$, Type II ( $\mathrm{M}=52,24.5 \% ; \mathrm{F}=52,21.8 \%)$, Type III $(\mathrm{M}=18,8.5 \% ; \mathrm{F}=24,10.1 \%)$, Type IV $(\mathrm{M}=19$, $9.0 \% ; \mathrm{F}=23,9.7 \%)$, Type $\mathrm{V}(\mathrm{M}=3,1.4 \% ; \mathrm{F}=1$, $0.4 \%),\left(\mathrm{X}^{2}=2.14, \mathrm{P}=0.83\right)$.

In table $7 \mathrm{~d}$, the distribution and association between lip print types and sex in the lower left quadrant were as follow: Type I $(\mathrm{M}=74,34.9 \%$; $\mathrm{F}=$ $87,36.6 \%)$, Type I' (M = 45, 21.2\%; F = 48, 20.2\%), Type II $(\mathrm{M}=63,29.7 \% ; \mathrm{F}=62,26.1 \%)$, Type III $(\mathrm{M}=$ $12,5.7 \% ; \mathrm{F}=25,10.5 \%)$, Type IV $(\mathrm{M}=16,7.5 \% ; \mathrm{F}=$ $16,6.7 \%)$, Type $\mathrm{V}(\mathrm{M}=2,0.9 \% ; \mathrm{F}=0,0.0 \%),\left(\mathrm{X}^{2}=\right.$ $6.24, \mathrm{P}=0.28)$.

\section{DISCUSSION OF FINDINGS Distribution and predominance}

In this study, observing across the entire population there were more of Type I, followed by Type II in the Lower Left Quadrant (LLQ) and Lower Right Quadrant (LRQ), more of Type III followed by Type IV in the Upper Right Quadrant (URQ) and more of Type III followed by Type II in the Upper Left Quadrant (ULQ). However, the distribution of Types II $(22.4 \%)$ and IV $(22.0 \%)$ in the ULQ was almost equal. Ghimire et al. [22] reported that only Type I was predominant in all the quadrants of the lip. Generally, there were more of type III lip print patterns and less of Type V in the URQ and ULQ. Similarly, LRQ and LLQ had more of Type I and less of Type V. In other words, the Upper lip had more of Type III while in the Lower lip, Type I occurred most but Type V was least observed in both parts. Generally there were more of Type I followed by Type II, III, I', IV, V in that order in the study population. The study observed a significant distribution between the type of pattern and the quadrant location; that is, the lip print pattern was distributed differently at the upper and lower lips.

\section{Gender difference in distribution}

In this study, all five (5) lip print types observed in the study were found on the lips of Nigerians; however, their distribution, varied between male and female. Significant differences were observed in some quadrants, while other quadrants despite having displayed differences, these were not statistically significant while other quadrants although displayed varying distributions but they were not significant. Generally, there were more of Type I, II, III, IV, I', V in that order among the female subjects whereas in male the order were Type I, II, equal distribution of III \& I', IV, V. In the URQ Type I, Type II and Type V were more frequently observed in males, while female displayed more of Type I', Type III and Type IV. It could be stated that to a large extent, the proportion and distribution of lip print types in URQ is influenced by gender. The study of Saraswathi et al. [2], Vijay et al. [23] and Qudusia et al. [11] reported that cheiloscopy was fundamental in the prediction of sex. The ULQ did not display any significant predominant lip pattern in males and females. However, Type I was observed 
more in males compared to the females, while Type I', Type II, Type III and Type IV was observed more in females compared to males but Type V was equally distributed in both genders. Therefore, the proportion and distribution of lip print types in the ULQ does not depend on the gender of an individual. There were no significant difference in the distribution of lip print types between male and female subjects in the LRQ, however, there were more of Types I, I' and II in both genders. Hence, the proportion and distribution of lip print types in the LRQ was not influenced by gender. The LLQ did not also show any significant difference between male and female.

Generally, there were more of Types I, II, I', III, IV and V in that order in males, whereas in females there were more of Types I, II, III, I', IV and V in that order. However, Types I, II, III, and V were predominant in females in comparison to males, with the reverse in Types I' and IV. This agrees with the study of Naeem et al. [24] who was of the opinion that Type I' was seen only in females while Types II, III, IV and $\mathrm{V}$ was seen in both genders. This study suggest that lip distribution is independent of the gender and what was seen in the upper right quadrant (URQ) could be by a coincidence and not strong enough to suggest that lip print distribution is dependent on gender. This is in line with the studies of Jain et al. [25] and Peeran et al. [26], but contrary to the findings of Karki [27], Yogesh et al. [28] and Ghimire et al. [22]

\section{CONCLUSION}

The findings of this study suggest that Type I is the most predominant lip print type, followed by Type II among the study population. However, Type III was predominant in the upper lip and Type I in the lower lip among the studied population.

The study showed that not all quadrants exhibited gender differences in the pattern of lip prints distribution. Only a one quadrant (Upper Right Quadrant) of lip prints can be said to have gender discriminatory indicators, and this maybe a mere coincidence. Thus, this study suggests that lip prints may not be a good predictive tool for gender.

\section{ACKNOWLEDGEMENTS}

We appreciate the entire management and staff of the Department of Anatomy, University of Port Harcourt and University of Port Harcourt Teaching Hospital.

\section{Author's contribution}

We write to state that all authors have contributed significantly, and that all authors are in agreement with the contents of the manuscript. 'Author A' (ThankGod Chukwumeka Omuruka) designed the study and protocol, wrote the first draft of the manuscript; 'Author B' (John Nwolim Paul) 'reviewed the design, protocol; 'Author C' (Chizindu Akubudike
Alikor) examined the intellectual content of the manuscript and 'Author D' (Chinyere O. Ndu-Akinla) did the literature search and analysis of the study. All authors read and approved the final manuscript.

\section{REFERENCES}

1. Kasprazak, J. (1990). Possibilities of chieloscopy. Forensic Science International, 46: 145-151.

2. Saraswathi, T.R., Mishra, G., \& Ranganathan, K. (2009). Study of Lip Prints. Journal of Forensic Dental Sciences, 1(1): 28-31.

3. Augustine, J., Barpande, S.R., \& Tupkari, J.V. (2008). Cheiloscopy as an Adjunct to Forensic Identification: A Study of 600 Individuals. Journal of Forensic Odontostomatology, 27(2): 201-209

4. Vats, Y., Dhall, J.K., \& Kapoor, A.K. (2012). Gender variation in morphological patterns of lip prints among some north Indian population. Journal of Forensic Dental Science, 4(1): 19-24.

5. Prabhu, R.V., Dinakar, A.D., Prabhu, A.D., \& Rao, A.P. (2012). Cheiloscopy: revisited. Journal of Forensic Dental Science, 4(1): 47-53.

6. Koneru, A., Nellithady, G.S., Ramesh, D.N.S.V., \& Patil, R. (2013). Comparison of lips prints in two different populations of India: Reflection based on preliminary examination. Journal of forensic Dental Sciences, 5(1):11-15.

7. Meril, A.S., Ramakrishna, A., Meera, J., \& Rani, N. (2013). Study of Fingerprint Patterns in Relationship with Blood Group and Gender. International Journal of Current Research, 5(12): 3994-3997.

8. Utsuno, H., Kanoh, T., Tadokoro, O., \& Inoue, K. (2005). Preliminary study of post mortem identification using lip prints. Forensic Science International, 149: 129-132.

9. Warwick, R., \& Williams, P. L. (1979). Gray Anatomia. 35th edition. Rio de Janeiro, Guanabara Koogan, 1137-1140; 1168-1173.

10. Sivapathasundharam, B., Prakash, P.A., \& Sivakumar, G. (2001). Lip prints (Cheiloscopy). Indian Journal of Dental Research, 12(4):234-7.

11. Qudusia, S., Shariff, M.H., Muhammed, A., \& Ramakrishna, A. (2014). Cheiloscopy: A Scientific Approach for Personal Identification. International Journal of Anatomy and Research, 2(4):668-672.

12. Kasprzak, J. (2000). Cheiloscopy. In: Siegel, J.A., Pekka, S.J., \& Geodfrey, C.K. eds. Encyclopedia of Forensic Sciences. 1st edition. Warsaw Academic Press, 358-361.

13. Ball, J. (2002). The Current Status of Lip Prints and their use for Identification. Journal of Forensic Odontostomatology, 20:43-6.

14. Adamu, L.H., Taura, M.G., Hamman, W.O., Ojo, S.A., Dahiru, A.U., Sadeeq, A.A., Umar, K.B. (2013). Relationship of thumb prints and lip prints among Nigerians. Journal of Dental and Medical Sciences, 9(2): 12-17. 
15. Tsuchihashi, Y. (1974). Studies on Personal Identification by means of lip prints. Forensic Science, 3: 233-284.

16. Wael, M.S., Assem, H.K., Hassan, F.Z., and ElOtiefy, M.A. (2005). Genetic Studies on the Inheritance of Lip Prints in Cleft Lip and Palate. Egypt Journal of Plastic and Reconstructive Surgery, 29(1): 9-12.

17. Randhawa, K., Narang, R. S., and Arora, P. C. (2011). Study of the Effect of Age Changes on Lip Print Pattern and Its Reliability in Sex Determination. Journal Forensic Odontostomatology, 29(2)45-51.

18. Molano, M.A., Gil, J.H., Jaramillo, J.A., \& Ruiz, S.M. (2002). Revista facultad de odontología universidad de antioquia. Rev. Fac. Odonto. Univ. Antioquia, 14: 26-33.

19. Kannan, S., Muthu, K., Muthusamy, S., \& Sidhu, P. (2015). Cheiloscopy - A Vital Tool in Crime Investigation. International Journal of Forensic Science and Pathology, 3(3): 89-93.

20. Karki, R.K. (2012). Lip Prints-an Identification Aid. Kathmandu University Medical Journal, 38(2):55-57.

21. Oghenemavwe, E.L., \& Osaat, R.S. (2015). An improvise Easy Digital Method for Palmar and Plantar Dermatoglyphics. Bioscience and Bioengineering, 1(3):85-89.

22. Ghimire, N., Ghimire, N., Nepal, P., Upadhyay, S., Budhathoki, S.S., Subba, A., \& Kharel, B. (2013).
Lip Print Pattern: an Identification Tool. Health Renaissance, 11(3):229-233.

23. Vijay, K.D., Pravir, B., \& Naveen, R. (2013). Efficacy of Cheiloscopy in Determination of Sex among South Indians. Journal of Clinical and Diagnostic Research, 7(10): 2193-2196.

24. Naeem, A., Maryam, A., Verma, A.K., Pankaj, K. (2015). Use of cheiloscopy as a tool for gender Dimorphism in Rural Indian Population. British Journal of Medicine and Medical Research, 10(3):1-6.

25. Jain, A.A., Patel, D.M., \& Pensi, C.A. (2013). Study of lip prints among the Gujarati population for personal identification. International journal of scientific research, 2(11): 398-399.

26. Peeran, S.W., Naveen, K.P.G., Abdalla, K.A., Azaruk, F.A., Manipady, S., \& Alsaid, F.M. (2015). A study of lip print patterns among adults of Sebha city, Libya. Journal of Forensic Dental Science, 7(1): 67-70.

27. Karki, R.K. (2012). Lip Prints-an Identification Aid. Kathmandu University Medical Journal, 38(2):55-57.

28. Yogesh, V., Jasmine, K.D., \& Kapoor, A.K. (2012). Gender variation in Morphological Patterns of Lip Prints among some North Indian Populations. Journal of Forensic Dental Science, 4(1):19-23. 